Western University

Scholarship@Western

FIMS Publications

Information \& Media Studies (FIMS) Faculty

2015

\title{
A Matter of Time and Academic Discipline? Exploring the Use of Resources
}

Lori McKay-Peet

Western University

Anabel Quan-Haase

The University of Western Ontario, aquan@uwo.ca

Dagmar Kern

Peter Mutschke

Follow this and additional works at: https://ir.lib.uwo.ca/fimspub

Part of the Library and Information Science Commons

Citation of this paper:

McKay-Peet, Lori; Quan-Haase, Anabel; Kern, Dagmar; and Mutschke, Peter, "A Matter of Time and Academic Discipline? Exploring the Use of Resources" (2015). FIMS Publications. 73.

https://ir.lib.uwo.ca/fimspub/73 


\title{
CAIS Paper: A matter of time and academic discipline? Exploring the use of resources
}

\author{
Lori McCay-Peet and Anabel Quan-Haase (Western University) \\ Dagmar Kern and Peter Mutschke (GESIS - Leibniz Institute for the Social Sciences)
}

\begin{abstract}
:
This paper reports on a survey of 26 social scientists and computer scientists. Through the vignette technique, resource use in situations in which scholars have a lot and very little time were explored. Findings suggest academic discipline and time may play a role in resource use.
\end{abstract}

\section{Résumé:}

\section{Introduction}

Connaway, Lanclos, and Hood (2013) write, "There is little understanding of what motivates individuals to use particular technologies or spaces when engaging with the information environment" (p. 290). Using one resource (e.g., library catalog) over another influences the quality of the sources gathered (Asher, Duke \& Wilson, 2013). Therefore, it is important to understand what factors influence resource use as this knowledge can inform digital literacy programs and the design and development of environments that are both useful and encourage repeated use. This paper explores two research questions.

\section{RQ1 Does type of resource use differ based on academic discipline?}

RQ2 Does resource use differ based on the amount of time a person has to devote to an information task?

\section{Prior research}

Academic discipline. While few studies have examined academic discipline, those that do suggest it is a factor in resource use. A survey of 3,498 academics from the United Kingdom found that while the largest share of participants (40\%) searched for information using a general-purpose search engine, medical and veterinary respondents were more likely to begin their search with a specific digital resource than respondents from other disciplines (Housewright, Schonfeld, \& Wulfson, 2013). Kim, Sin, and Tsai (2014) examined how discipline affects social media use through a web-based survey of 809 university students and found significant differences in university students' use of different types of social media across academic disciplines (e.g., social science, engineering).

Time. Another potential explanation for resource use is time: "Time is one of the main contextual factors of information seeking" (Savolainen, 2006, p. 110). Savolainen identified three approaches to examine time in the context of information seeking: time as 1) a characteristic of a situation and time as an aspect of 2) accessibility and 3) the information seeking process. Liu et al. (2014) note, "Time constraint as a contextual factor has not been widely investigated in information retrieval research" (p. 224). A within-subjects experiment with 40 undergraduate students found that time constraint on search tasks shares a relationship with affect and knowledge acquisition (Liu et al., 2014). 
Findings from a study in which 269 participants completed a series of information seeking tasks suggests that time constraint has the potential to influence search process (Crescenzi, Capri, \& Arguello, 2013). While prior research has focused on search strategies and perceptions within a given digital resource, we know of no studies that have examined time constraint as a factor in what resources are selected for use.

\section{Methods}

The web-based survey $(N=26)$, using open source Limesurvey software, took place from June 11 to July 1, 2014 in Germany. A portion of the participants completed the survey in-person $(n=15)$ as part of a larger study, which involved the completion of an exploratory task in either ACM Digital Library [http://dl.acm.org] or GESIS' Sowiport [http://sowiport.gesis.org] (task findings not reported here). Others $(n=11)$ were recruited to complete the survey online. Social scientists $(n=12 ; 46 \%)$ at the GESIS Leibniz Institute for the Social Sciences responded to an email invitation to participate in the study. To recruit computer scientists $(n=14 ; 54 \%)$, invitations were sent to colleagues who were asked to forward the invitation to master's and $\mathrm{PhD}$ students and colleagues. Those completing the study in-person were given monetary incentive for participation (10€, approximately $\$ 15 \mathrm{CAD})$. Participants were predominantly male $(n=$ $18 ; 69 \%$ ) with a mean age of 35 .

The survey used the vignette technique. Vignettes "are short stories about hypothetical characters in specified circumstances, to whose situation the interviewee is invited to respond" (Finch, 1987, p. 105). Finch argued that while this technique cannot predict how respondents would act in a situation, it allows respondents to distance themselves and indicate what they believe a third person should do in the situation. The vignette technique thus reveals cultural norms, or behaviours typical of a specific group -- in this case, scholars looking for information.

Master's students $(n=2 ; 8 \%)$ were given vignettes that described Jan: a master's student who "has research interests similar to yours," completing a class paper. The remainder ( $n$ $=24 ; 92 \%$ ), including PhD students, post docs, and professors, were given vignettes that described Anna: a post doc at a German university "in a field similar to your own," who was preparing a grant application that would help her expand on her PhD research.

The vignettes represent four information-intensive stages of Jan and Anna's task. Our study embeds time as a characteristic of each of the situations described in the vignettes. In the first two stages (Time), Jan and Anna have lots of time to search for a specific item and explore. In the last two stages (No Time), Jan and Anna have very little time to search and explore. Participants were asked to recommend resources to Jan or Anna in each of the four stages.

For example, in the first Time stage, a situation was described in which Anna had set aside some time to explore potential project ideas. Participants were then asked,

In your experience, what search engines, applications, databases, and websites would you most likely recommend Anna use considering she has lots of time today to explore potential research project ideas?

Participants were asked to respond to each of the resources they indicated they use on a five-point scale of "not likely at all" (1) to "very likely" (5). 
Survey responses were downloaded to SPSS. Missing values were recoded as 1 (not likely at all). To answer our research questions, the means of the resources in the two Time stages were calculated, as were means of the two No Time stages.

\section{Findings}

The figures below illustrate the resources social scientists (Figure 1) and computer scientists (Figure 2) would recommend Jan or Anna use when they have Time or No Time to search or explore. These figures include only those resources with a mean $>1$ : resources that were "not likely at all" to be recommended were not included in the figures.

Top Resources. The top three resource recommendations by scholars, regardless of time, included Google and Google Scholar as well as either GESIS Services (social scientists) or ACM Digital Library (computer scientists). This finding is similar to that of Kemman et al. (2012). Kemman et al.'s survey of 288 humanities scholars in the Netherlands and Belgium found these scholars were regular users of Google, Google Images, and Google Scholar, followed by YouTube and JSTOR.

Social Scientists. We found no significant differences between the Time and No Time conditions using a dependent t-test (pair-wise comparisons) of the top four social science resources (Online library, Google, GESIS Services, Google Scholar).

Computer Scientists. A dependent t-test of this group's top four resources indicate that Google Scholar, ACM Digital Library, and SpringerLink were significantly more highly recommended when there is Time than No Time at the $p<.05$ level. No significant differences for Google were found. Findings suggest that all digital resources, regardless of whether they are easily accessed search engines and websites or digital resources behind firewalls, are more likely used when there are fewer time constraints.

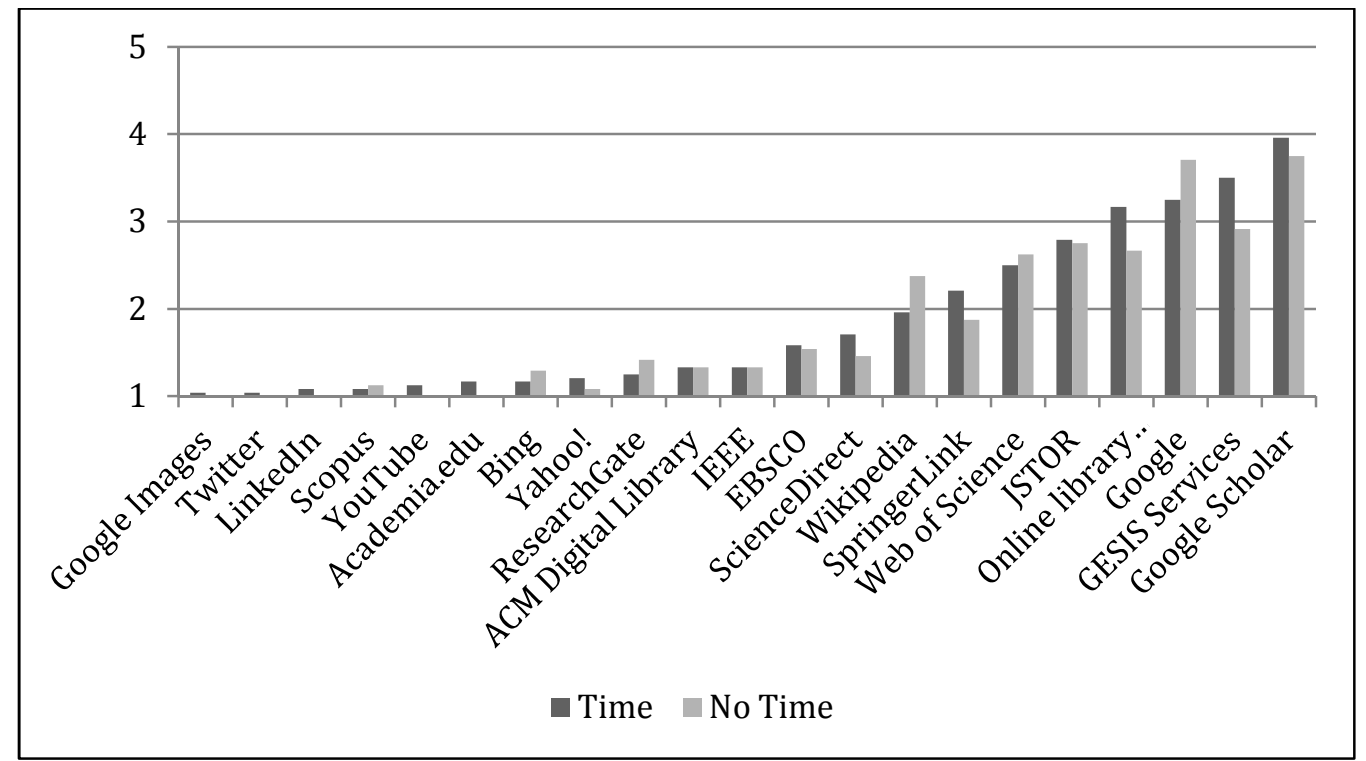

Figure 1 Recommendation of resources by social scientists when there is Time and when there is No Time 


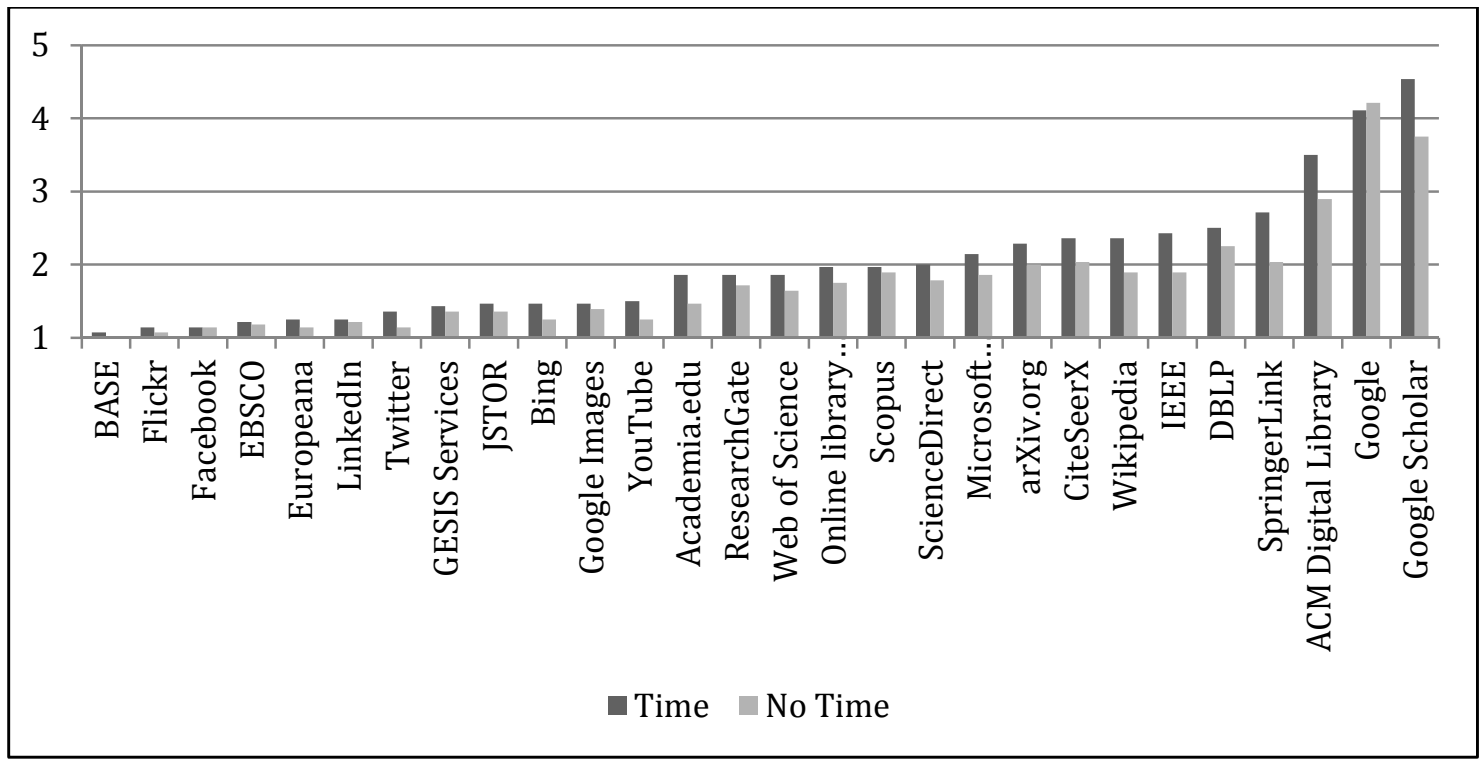

Figure 2 Resources computer scientists recommend Jan or Anna use when there is Time and when there is No Time

What is evident from the findings is that Google and Google Scholar are important resources, regardless of academic discipline and time. Further exploration of the ratings by individual participants suggests, however, that while Google products are very popular, other, more specialized digital resources, are also used. While the majority of participants $(n=23)$ indicated they would likely or very likely recommend Google or Google Scholar when Jan and Anna have Time, $74 \%$ of these participants $(n=17)$ equally recommended at least one other resource. Similarly, while most participants $(n=$ $22)$ indicated they would likely or very likely recommend Google or Google Scholar when Jan and Anna have No Time, $86 \%$ of these participants $(n=19)$ equally recommended at least one other resource. As Wilson notes, "Google is really good. For what it does" (2010, p. 4). Digital resources other than Google are needed to complement a search for scholarly information.

\section{Conclusion}

We used the vignettes technique to explore what digital resources social scientists and computer scientists use under different information seeking situations. While Google and Google Scholar appear to be the 'go-to' resources for the majority of scholars described in this paper, Google products are part of a suite of resources on which these scholars rely. Findings suggest that both time and academic discipline may influence choice of digital resource but due to the limitations of this research, including the small sample size, more research is needed. A diary study, for example, could examine what suite of resources is used when information seekers are under different levels of time constraint, motivations behind selection, and outcomes related to resource use. Understanding what factors influence resource use will inform efforts to improve digital literacy programs and the development of digital resources that meet the needs of scholars.

\section{References}

Asher, A. D., Duke, L. M., \& Wilson, S. (2013). Paths of Discovery: Comparing the Search Effectiveness of EBSCO Discovery Service, Summon, Google Scholar, and Conventional Library Resources. College \& Research Libraries, 74(5), 464-488. 
Connaway, L. S., Lanclos, D., \& Hood, E. M. (2013). "I find Google a lot easier than going to the library website." Imagine ways to innovate and inspire students to use the academic library. In ACRL 2013 (pp. 289-300).

Crescenzi, A., Capra, R., \& Arguello, J. (2013). Time pressure, user satisfaction and task difficulty. Proceedings of the American Society for Information Science and Technology, 50(1), 1-4. doi:10.1002/meet.14505001121

Finch, J. (1987). The vignette technique in survey research. Sociology, 21(1), 105-114.

Housewright, R., Schonfeld, R. C., \& Wulfson, K. (2013). Ithaka S + R I Jisc | RLUK UK Survey of Academics 2012 (pp. 1-92).

Kemman, M., Kleppe, M., \& Scagliola, S. (2012). Just Google it: Digital research practices of humanities scholars. In C. Mills, M. Pidd, \& E. Ward (Eds.), Proceedings of the Digital Humanities Congress 2012. Sheffield: HRI Online Publications. Retrieved from http://www.hrionline.ac.uk/openbook/chapter/dhc2012-kemman

Liu, C., Yang, F., Zhao, Y., Jiang, Q., \& Zhang, L. (2014). What does time constraint mean to information searchers? In Proceedings of the 5th Information Interaction in Context Symposium on - IIIX' 14 (pp. 227-230). New York, New York, USA: ACM Press. doi:10.1145/2637002.2637029

Savolainen, R. (2006). Time as a context of information seeking. Library \& Information Science Research, 28(1), 110-127. doi:10.1016/j.lisr.2005.11.001

Wilson, M. L. (2010). From Keyword Search to Exploration: Designing Future Search Interfaces for the Web. Foundations and Trends® in Web Science, 2(1), 1-97. doi:10.1561/1800000003 